\title{
METODOLOGIAS ATIVAS NO ENSINO SUPERIOR: PARA ALÉM DA SUA APLICAÇÃO, QUANDO FAZEM A DIFERENÇA NA FORMAÇÃO DE PROFISSIONAIS?
}

\author{
MASETTO, Marcos Tarciso*
}

\begin{abstract}
RESUMO
O objetivo a que nos propomos neste artigo é identificar em que condições a utilização das Metodologias Ativas no Ensino Superior faz realmente a diferença na formação de profissionais. Para responder a este objetivo trazemos, numa abordagem de pesquisa qualitativa, um estudo teórico desta questão buscando os significados com os quais autores contemporâneos como Ken Bain, Hargreaves, Imbernón, Pozo, Saturnino de la Torre, Veen, Vrakking, Zabalza, Moran, Bacich e Masetto vêm discutindo este objetivo. Relacionamos estes estudos com nossa experiência docente, pesquisas e publicações desde 2007 sobre essa temática. Isso nos permitiu apresentar algumas respostas às indagações feitas. Para que as Metodologias Ativas façam a diferença no ensino superior, sua utilização deve estar integrada aos objetivos de formação profissional, ao protagonismo do aluno e a uma atitude de mediação pedagógica do professor.
\end{abstract}

PALAVRAS-CHAVE: Metodologias Ativas. Formação Profissional. Mediação Pedagógica. Protagonismo do Aluno.

\footnotetext{
* Professor da Pontifícia Universidade Católica de São Paulo, PUC-SP. 


\title{
MASETTO, Marcos Tarciso*
}

\begin{abstract}
The purpose of this article is to identify under what conditions the use of Active Learning Methodologies in Higher Education really makes the difference in the training of professionals. From a qualitative research approach, we have developed a theoretical study seeking the meanings with which contemporary authors like Ken Bain, Hargreaves, Imbernón, Pozo, Saturnino de la Torre, Veen Vrakking, Zabalza, Moran, Bacich, and Masetto have been discussing this question. In the next step, we relate these studies to our teaching experience, research, and publications since 2007 on this subject. The studies allowed us to answer the question and conclude that for Active Learning Methodologies to make a real difference in higher education, its use must be integrated with the objectives of professional training, the student's protagonism and an attitude of pedagogical mediation of the teacher.
\end{abstract}

KEYWORDS: Active Learning Methodologies. Professional Qualification. Pedagogical Mediation. Protagonism. 


\section{INTRODUÇÃO}

A Docência no Ensino Superior na contemporaneidade se apresenta com trilhas abertas para inovações, entre as quais se destacam as Práticas Pedagógicas Inovadoras buscando a dinamização de tempos e espaços de aprendizagem, conhecidas também como Metodologias Ativas.

Congressos Nacionais e Internacionais, Workshops, Encontros, Seminários debatem metodologias inovadoras como Problem Based Learning (PBL) ou Aprendizagem Baseada em Problemas (ABP), Tecnologias Digitais de Informação e Comunicação (TDICs), Sistemas Tutoriais para EaD, Laboratórios de Simulação, Peer Instruction, Ensino Híbrido, Perestroika (Experience Learning), Team- Based Learning (TBL), Project Based Learning, e outras. Cursos de treinamento de professores para conhecimento e uso das respectivas metodologias são propostos e realizados.

Em 2007, professores da Escola Politécnica da USP tendo participado de vários cursos sobre a formação pedagógica de docentes para o Ensino Superior sob nossa orientação, construíram suas aulas, nas diversas disciplinas, com práticas e técnicas pedagógicas ativas que incentivaram os alunos a assumir e desenvolver seu processo de aprendizagem e formação profissional como engenheiros.

O resultado destas experiências se socializou em um livro escrito por 11 desses professores e que se intitulou: "Ensino de Engenharia - Técnicas para otimização das aulas". No primeiro capítulo escrito por nós e que se intitulou "Técnicas diferenciadas colaboram para a aprendizagem na Engenharia” comentávamos:

A diferenciação e a variedade de técnicas quebram a rotina das aulas e assim os alunos se sentem mais animados a frequentá-las; facilitam a participação e incentivam as atividades dinâmicas durante o período das aulas, desenvolvem a curiosidade dos alunos e os instigam a buscarem, por iniciativa própria, as informações de que precisam para resolver problemas ou explicar fenômenos que fazem parte de sua vida profissional.

Novas técnicas de aprendizagem colaboram com os alunos quando seu desafio é resolver um problema, construir um projeto, produzir um artefato, operar um recurso tecnológico; favorecem a aprendizagem colaborativa entre os alunos e a integração da teoria com a prática....

No entanto, não são elas sozinhas que podem ajudar na aprendizagem.... Para analisarmos a eficácia do uso de técnicas diferenciadas, é necessário 
discutir três pontos: sua vinculação aos objetivos de aprendizagem, a postura do professor em sua aplicação e o processo de avaliação coerente com seu uso (MASETTO, 2007, p. 17-19).

Neste momento em que surge com nova força e modalidades diversas a questão da utilização de Metodologias Ativas, entendemos que faz sentido retomarmos, em novo contexto, o debate sobre "a eficácia do uso de técnicas diferenciadas" no Ensino Superior.

O título que encabeça este artigo explicita nosso objetivo: identificar em que condições a utilização das Metodologias Ativas no Ensino Superior faz realmente a diferença na formação de profissionais.

Para responder a este objetivo, pretendemos apresentar um estudo teórico envolvendo autores contemporâneos que vêm se debruçando sobre essas questões como Ken Bain, Hargreaves, Imbernón, Pozo, Saturnino de la Torre, Veen, Vrakking, Zabalza . Moran, Bacich e Masetto.

Esse estudo teórico se apresentará entrelaçado com pesquisas e estudos em cursos de Mestrado e Doutorado, com pesquisas e publicações realizadas por nós em nossa vida acadêmica e com parceiros integrantes do Grupo de Formação de Professores e Paradigmas Curriculares (FORPEC) da PUCSP.

Partimos da compreensão educacional de Metodologias Ativas:

- como estratégias que pretendem incentivar e desenvolver o protagonismo e a autonomia do aluno em seu processo de aprendizagem e formação profissional;

- que incentivam os processos do aprender individual e colaborativo;

- são instrumentos escolhidos para o alcance dos vários e diferentes objetivos de formação profissional;

- contam com a atitude de mediação pedagógica por parte do professor para sua implementação;

- permitem ação e trabalho nos diferentes espaços de aprendizagem: presenciais nas universidades, em ambientes profissionais; em ambientes virtuais e a distância; ambientes que constituem o contexto mais amplo em que as instituições educacionais se encontram inseridas;

- produzem resultados concretos de aprendizagem: textos, projetos, resolução de problemas, atuação competente em situações profissionais, comunicação de trabalhos e projetos, debates sobre temas controvertidos. 
A partir desta concepção de Metodologias Ativas queremos dialogar sobre três aspectos imprescindíveis para que possam fazer a diferença na formação de profissionais para a contemporaneidade: alinhamento claro entre metodologias ativas e objetivos de formação profissional, o protagonismo do aluno e a mudança de atitude do professor

\title{
2 ALINHAMENTO EXPLÍCITO ENTRE METODOLOGIAS ATIVAS E OBJETIVOS DE FORMAÇÃO PROFISSIONAL
}

Essencial no conceito de metodologias ativas é sua característica de instrumentalidade pela qual sempre se referem a determinados objetivos e em função dos quais se constituem, e para cuja consecução precisam ser eficientes.

Em se tratando do emprego das Metodologias Ativas no Ensino Superior, um primeiro passo é a identificação dos objetivos de uma formação profissional.

Esta formação é construída através de um processo de aprendizagem. Não se ensina uma profissão: “aprende-se", desenvolve-se, conquista-se uma formação profissional com o desenvolvimento de conhecimentos, de competências e habilidades, e de atitudes e valores profissionais. Vários objetivos que para serem alcançados precisarão contar com a colaboração de uma diversidade de técnicas e métodos adequados para cada um deles. $\mathrm{O}$ sujeito que constrói esse processo de aprendizagem é o aprendiz em parceria e colaboração com seus colegas e com o professor.

Ken Bain (2007) perguntando "a los mejores profesores universitários” o que fazem quando "ensinam", obteve como resposta:

\begin{abstract}
procuram criar o que acabamos denominando 'um entorno para a aprendizagem crítica natural'. Nesse entorno, as pessoas aprendem confrontando-se com problemas importantes, atraentes ou intrigantes, com atividades reais que lhes colocarão desafios ao abordar ideias novas, rever seus conhecimentos prévios e analisar seus modelos mentais sobre a realidade. Nestas condições, os estudantes experimentam uma sensação de controle sobre sua própria educação, trabalham em colaboração com outros, creem que seu trabalho será avaliado honestamente e se realimentam com apoio de estudantes com mais experiência (BAIN, 2007, p. 29).
\end{abstract}

Para esta "aprendizagem crítica natural” precisamos da colaboração de Metodologias Ativas para incentivarem e proporcionarem condições para o desenvolvimento de 
conhecimentos, de competências e habilidades, e de atitudes e valores dos profissionais em suas múltiplas dimensões, contextualizadas na sociedade do conhecimento em que vivemos

Hargreaves (2004), comenta:

[...] ensinar na sociedade do conhecimento, e para ela, está relacionado com a aprendizagem cognitiva sofisticada, com um repertório crescente e inconstante de práticas de ensino informadas por pesquisa, aprendizagem e auto acompanhamento profissional contínuo, o trabalho coletivo, parceria de aprendizagem, desenvolvimento e utilização da inteligência coletiva e cultivo de uma profissão que valorize a solução de problemas, a disposição para o risco, a confiança profissional, lidar com a mudança e se comprometer com a melhoria permanente (HARGREAVES, 2004, p. 4546).

O desenvolvimento da área do conhecimento adquiriu novas características: o aumento significativo da quantidade de informações, relacionada ao desenvolvimento das pesquisas; o acesso em tempo real e imediato a essas informações graças às Tecnologias Digitais de Informação e Comunicação (TDICs) por todas as pessoas; à expansão dos Cursos de Especialização e Pós Graduação (Stricto e Lato Sensu) e ao incentivo atual da Aprendizagem ao Longo da Vida.

Aprender por pesquisa e descoberta, construir conhecimento interdisciplinar e Interprofissional, explorar novas áreas de conhecimento vinculadas às novas carreiras profissionais e aos problemas surgidos em nossos tempos - desafios à ciência e à tecnologia se apresentam como os atuais parâmetros do conhecimento a ser desenvolvido junto aos nossos alunos de graduação.

E as Metodologias Ativas são chamadas a colaborar com essa formação.

Os professores devem ser capazes de construir um tipo especial de profissionalismo, que não pode ser aquele antigo, no qual tinham autonomia para ensinar da forma como bem quisessem ou que lhes fosse mais familiar... mas, devem se dedicar a construir um profissionalismo na docência para promover a aprendizagem cognitiva profunda, aprender a ensinar por meio de maneiras pelas quais não foram ensinados, comprometer-se com a aprendizagem profissional contínua, trabalhar e aprender em equipes de colegas, construir uma capacidade para a mudança e o risco, estimular a confiança nos processos (HARGREAVES, 2004, p. 40).

Há que se perceber que Hargreaves (2004) chama os professores para assumirem participação nessa proposta de construção do conhecimento, criarem "um profissionalismo na docência para promover a aprendizagem cognitiva profunda por meio de maneiras pelas quais não foram ensinados" (HARGREAVES, 2004, p. 40). 
O desenvolvimento de habilidades e competências para o exercício profissional se configura como uma segunda dimensão da aprendizagem nos cursos de graduação. Além de habilidades específicas para cada área profissional e suas especialidades, atualmente se exigem habilidades/ competências para atuar em equipes interdisciplinares e interprofissionais, uso de conhecimentos interdisciplinares, desenvolvimento contínuo de pesquisa que mantenha o profissional atualizado. A resolução de situações profissionais com eficiência e eficácia exige habilidade de mobilizar recursos cognitivos, técnicos, operacionais, de trabalho em equipe; de experiências pessoais como profissional. Habilidades para empreendedorismo, proatividade, iniciativa, diálogo, solução de problemas. Habilidades para usar e trabalhar com as Tecnologias Digitais de Informação e Comunicação.

Nossa reflexão se alinha à análise de Pozo (2002). É necessário, diz o autor:

aprendizagem de estratégias para planejar, tomar decisões e controlar a aplicação das técnicas, para adaptá-las às necessidades específicas de cada tarefa. As estratégias se tornam necessárias diante de situações novas ou muito complexas, que constituem um verdadeiro problema, uma encruzilhada de opções ou caminhos [...]. As estratégias são adquiridas por processo de reestruturação da própria prática, produto de uma reflexão e tomada de consciência sobre o que fazemos e como o fazemos (POZO, 2002, p. 78).

Pozo destaca aprendizagens de habilidades e competências (habilidades, destrezas ou estratégias (POZO, 2002, p. 77) para realizar coisas concretas: planejar, tomar decisões, controlar aplicação de técnicas, adaptação das habilidades a novos e diferentes contextos e necessidades, e nos aponta uma direção para a aquisição e as mudanças da própria prática: uma reflexão sobre ela mesma, analisando o que fazemos e como o fazemos.

Zabalza (2014), também destaca a importância do desenvolvimento de habilidades e competências na formação profissional como, por exemplo, a análise das situações, a tomada de decisões e a resolução de problemas a partir da prática profissional como metodologia de aprendizagem. Assim se expressa:

A aprendizagem de processos complexos de atuação profissional incluem a análise das situações, a tomada de decisões e a resolução de problemas, [...] que os profissionais enfrentam ao lidar com situações variáveis, e pouco definidas às quais devem dar sentido e organizar para saber como agir quando se encontram nelas [...]. Este conhecimento prático dos profissionais não se baseia nas evidências gerais a partir da pesquisa acadêmica, mas sim 
na boa prática dos profissionais. É um conhecimento em ação e não um conhecimento acadêmico (ZABALZA, 2014, p. 182-183).

Poderíamos concluir com Zabalza: habilidades e competências se constroem com metodologias que incentivem uma aprendizagem em ação e não através de informações acadêmicas em espaços universitários.

$O$ desenvolvimento de atitudes e valores profissionais completa como terceira dimensão a formação de profissionais exigida pela nossa sociedade.

Responsabilidade social, ética, cidadania, valorização da pesquisa, do trabalho em equipe, da colaboração, da abertura para o novo, para o atual, para as novas demandas da sociedade, para a complexidade e interdisciplinaridade dos problemas, para uma atuação interprofissional, para uma atitude de disponibilidade e serviço para a sociedade são algumas atitudes e posturas esperadas dos profissionais. Com que metodologias podemos contar para aquisição e desenvolvimento dessas atitudes?

Aprender a discutir os aspectos sociais, éticos, culturais, políticos, econômicos que se encontram no bojo das soluções técnicas e científicas que são tomadas pelos profissionais no exercício de sua profissão é um excelente exercício de aprendizagem com relação a atitudes.

A UNESCO (1998) em sua Declaração Mundial sobre Educação Superior no Século XXI. Visão e Ação, assumindo apresentar um marco referencial para a mudança e o desenvolvimento da Educação Superior em todo o mundo, destaca com muita coragem as atitudes e os valores a serem desenvolvidos com professores e alunos do Ensino Superior:

Afirmamos que as missões e os valores fundamentais da educação superior devem ser preservados, respeitados e expandidos a fim de educar e formar pessoas altamente qualificadas, cidadãs e cidadãos responsáveis [...]; prover oportunidades para a aprendizagem permanente [...] de modo a educar para a cidadania e para participação plena da sociedade [...] promover, gerar e difundir conhecimentos por meio da pesquisa [...] contribuir na proteção e na consolidação dos valores da sociedade [...] cidadania democrática [...] perspectivas críticas e independentes, opinar em problemas éticos, culturais e sociais [...] reforçar o seu papel de serviço extensivo à sociedade (UNESCO, 1998, p. 16-22).

Com a preocupação de explicitar a relevância do desenvolvimento de atitudes e valores integrando o processo de aprendizagem, Pozo (2002) reflete:

Nossa capacidade de aprendizagem seria muito limitada se não estivesse amplificada pela cultura e, de modo mais imediato, pela exposição a contextos sociais que dirigem e encaminham nossa aprendizagem. Portanto, num sentido amplo, todas nossas aprendizagens são aprendizagens sociais 
ou culturalmente mediadas, já que se originam em contextos de interação social, como as relações familiares, a escola, ou os ambientes de trabalho ou profissionais [...]. Um âmbito especialmente importante da aprendizagem humana é a aquisição e mudança de atitudes [...]. Os aprendizes, em sua tarefa profissional de aprender, costumam adotar, de forma muitas vezes implícita, atitudes não só em relação à sua própria aprendizagem [...], como também em relação ao que estão aprendendo [...] e as relações sociais que estão envolvidas nessa aprendizagem [...]. As atitudes implicam não só uma forma de se comportar nessas situações ou diante dessas pessoas, como também uma valoração de um conhecimento social (POZO, 2002, p. 192195).

Com relação à formação profissional, discutindo essa mesma questão de desenvolvimento de atitudes e valores, Zabalza (2014) assim se expressa, comentando a atividade de estágio no ensino superior:

Esse tipo de práticas (o estágio) reforça na experiência do aluno a possibilidade de enriquecer sua consciência social e sua capacidade para analisar e desenvolver propostas de melhoria da comunidade [...]. Trata-se de articular uma experiência de trabalho em cenários profissionais reais, onde os estudantes aprendem a ir além das análises técnicas das atuações concretas que são chamados a realizar, para incluir também em sua reflexão aspectos éticos e políticos que os ajudem a entender por que as coisas são como são e em que medida sua atitude como profissionais poderá ajudar a enfrenta-las adequadamente (ZABALZA, 2014, p. 186).

A dificuldade de se trabalhar no Ensino Superior com o desenvolvimento de atitudes com futuros profissionais está relacionada a quatro fatores: os currículos de graduação praticamente não abrem espaços para esta formação; a cultura pedagógica dos docentes do Ensino Superior os faz entender que seu papel é apenas transmitir aos alunos informações específicas de sua área de conhecimento e deles cobrar uma reprodução destas informações; a cultura dos alunos que ainda hoje entendem que vêm à faculdade apenas para tirar notas e serem aprovados nas disciplinas da grade curricular, o que faz estranharem quando problemas sociais, éticos, políticos, educacionais, econômicos, de saúde são trazidos para estudo; por último, dispormos de poucas técnicas, metodologias e práticas pedagógicas adequadas para este tipo de aprendizagem e formação.

A reflexão sobre a primeira de nossas questões neste artigo: a que objetivos atende o emprego das Metodologias Ativas nos levou a compreender que, no ensino superior, as Práticas Pedagógicas Inovadoras, ou Metodologias Ativas devem se perguntar se e como 
colaboram com o desenvolvimento de uma formação profissional pluridimensional envolvendo desenvolvimento de conhecimentos, de competências e habilidades, e das atitudes. Uma resposta que seja positiva a esta pergunta poderá garantir-lhes uma presença significativa na formação de profissionais no ensino superior.

\section{O ALUNO PROTAGONISTA}

Partimos da compreensão educacional de Metodologias Ativas: como estratégias que pretendem incentivar e desenvolver o protagonismo e a autonomia do aluno em seu processo de aprendizagem e formação profissional;

Este aluno que chega hoje à universidade, no dizer de Veen e Vrakking (2009):

nasceu usando múltiplos recursos tecnológicos desde a infância que permitiram a ele ter um controle sobre o fluxo de informações, lidar com informações descontinuadas e com a sobrecarga de informações, mesclar comunidades virtuais e reais, comunicarem-se e colaborarem em rede e de acordo com suas necessidades (VEEN; VRAKKING, 2009, p. 12).

Masetto (2015) comenta:

Enquanto através dos aparelhos eletrônicos o jovem se encontra conectado, participante, compartilhando, trocando informações e opiniões, discutindo, tomando decisões, combinando programas, alterando os pontos de interesse, colocando-se numa posição de controle do processo, nas instituições escolares de modo geral cabe-lhe obedecer, seguir as normas e deveres, ouvir passivamente os professores em aula, realizar atividades planejadas e apresentadas pelo professor. Os jovens prezam por demais sua autonomia, sua proatividade, sua iniciativa e liberdade que os colocam no comando de seus contatos, de suas atividades (MASETTO, 2015, p. 9).

Os jovens querem descobrir a relevância do que aprendem e de seu uso na vida cotidiana Eles precisam identificar esta relevância nos conteúdos que se lhes apresenta, assim como nos métodos de ensino (Metodologias Ativas) que se lhes propõem e no processo de avaliação que se combina, podendo nesse clima participar e ser protagonista em seu processo de formação, no planejamento, utilização e aproveitamento das Metodologias Ativas, estar no controle dele e caminhar para uma autonomia profissional.

Hoje, a construção do conhecimento se faz a partir de pesquisas que trazem novas teorias, críticas aos conhecimentos anteriormente estabelecidos, novos problemas e respectivas soluções, num movimento contínuo de evolução e progresso científico e 
tecnológico, exigindo de todos, professores e alunos, trabalho com informações descobrindo seu significado e relevância para a vida profissional, aprofundando os aspectos multi e interdisciplinares dos problemas a serem equacionados, num contexto de mudanças.

Neste início do século XXI, o aluno como protagonista de seu processo de formação, trabalha pelo seu desenvolvimento na área cognitiva construindo conhecimento interdisciplinar e com pesquisa; na área de habilidades vivenciando situações práticas profissionais, integrando teoria e prática, resolvendo problemas e casos reais ou simulados, treinando algumas habilidades específicas; desenvolvendo atitudes na discussão de valores presentes em tomadas de decisão profissional.

As pessoas tendem a aprender mais efetivamente (de forma que lhes influencia duradoura, substancial e positivamente em sua maneira de agir, pensar ou sentir) quando: buscam resolver problemas (intelectuais, físicos, artísticos, práticos ou abstratos) que consideram intrigantes, atraentes ou importantes, num contexto de desafios; quando podem trabalhar em colaboração com os outros estudantes para superar os problemas; quando podem receber feedbacks de colegas com mais experiências (BAIN, 2007, p.124).

As pessoas tendem a aprender mais efetivamente como protagonistas na exploração do ambiente profissional para sua formação aplicando os conhecimentos teóricos em situações de atividade profissional, planejando e realizando estágio e visitas técnicas em parceria com seus professores, descobrindo novas modalidades de exercício de sua profissão, como por exemplo, trabalhando com conhecimento e atuação em equipes interdisciplinares e interprofissionais. A realização da auto-avaliação lhe proporciona maior conhecimento de si mesmo, de suas potencialidades a serem desenvolvidas e de seus limites a serem superados.

A aprendizagem é um processo complexoe compartilhado. Entrre as diferentes estruturas de mediação, o prórpio estudante é, com certeza, a mais importante, já que filtra os estímulos, organiza-os, processa-os, constroi com eles os conteúdos de aprendizagem, ao final, age a partir dos conteúdos e das habilidades assimilados (ZABALZA, 2004, p. 196).

Em síntese, é o aluno assumindo sob seu controle o encaminhamento de sua formação profissional em equipe com seus colegas e com seus professores:

O Aluno-Parceiro com novas atitudes: Vem para aprender, com proatividade (protagonismo), com participação na programação e realização das atividades, dentro do 
cronograma combinado, como corresponsável e coparticipante com professor e colegas pelo seu processo de formação profissional.

A utilização de Metodologias Ativas levará em conta estes diversos aspectos que constituem uma atitude de protagonismo do aluno para selecionar aquelas que são próprias e adequadas para desenvolvê-los criando oportunidades de participação, envolvimento e comprometimento com a construção de seu processo de formação.

\section{A MUDANÇA DE ATITUDE DO PROFESSOR}

O motivo da reflexão sobre este terceiro aspecto que pode fazer a diferença na utilização das Metodologias Ativas para a formação de profissionais tem origem em algumas de nossas observações.

Com efeito, este mesmo movimento de expansão das metodologias ativas trazem consigo a preocupação de treinamento de professores para aplicarem corretamente tais técnicas em suas aulas, incluindo-se apresentação de recursos próprios para isso, materiais já elaborados (como por exemplo, livros, artigos, vídeos, manuais, mobiliários), distribuição de espaço físico, e outros mais.

Compreendemos estas preocupações, mas delas inferimos o seguinte: parecem nos dizer que adquirida a compreensão da técnica e aplicada corretamente, inclusive com o uso dos recursos indicados, por professores bem treinados, automaticamente os resultados delas esperados acontecem nos mais diferentes contextos.

E aqui a nossa dúvida e a nossa questão: não nos parecem suficientes essas condições para que estas metodologias ativas façam a diferença quanto à formação de nossos profissionais.

Entendemos que para fazer a diferença, as metodologias ativas, além de serem compreendidas em sua concepção, usadas em função de alcançar os objetivos de formação pretendidos e aplicadas corretamente nos seus detalhes, para fazerem a diferença no processo de aprendizagem exigem outro requisito: repensar novas atitudes do professor, envolvido e participante com o aluno no processo de aprendizagem e formação profissional.

As atitudes apropriadas para a docência no ensino superior no século XIX, quando do início dos cursos de graduação no Brasil, perpetuando-se até nossos dias exigem serem repensadas à luz dos atuais objetivos de formação de nossos profissionais, à luz das Diretrizes 
Curriculares Nacionais para as diferentes carreiras profissionais e das propostas da UNESCO (1998) para as Universidades de todo o mundo.

Atitudes tradicionais de docentes universitários comprometerão tanto um processo de aprendizagem como a tentativa de usar Metodologias Ativas para fazerem a diferença na formação profissional.

Busca-se repensar as atitudes do professor.

Um professor que sem deixar de lado seus conhecimentos, suas pesquisas, sua experiência profissional descobre seu novo papel de mediador pedagógico e de parceiro do aluno na construção da aprendizagem e da formação profissional.

Um professor que se coloca como um facilitador, incentivador ou motivador da aprendizagem; que ativamente colabora para que o aprendiz chegue aos objetivos de sua formação profissional; que manifesta disponibilidade para colaborar na superação das dificuldades do aluno; que coloca o aprendiz frente a frente com questões éticas, sociais, profissionais.

Um professor mediador e parceiro que favorece o surgimento do aprendiz parceiro que assume a atitude de aprender, com atitude corresponsável pelo processo da formação.

Imbernón (2012) descreve a mediação pedagógica como:

Professores e alunos compartilham a atividade de aprender [...]. Os professores promovem e organizam as atividades de participação. $\mathrm{O}$ estudante é visto como um sujeito ativo que adquire, processa e avalia seu conhecimento. Os professores devem trabalhar na criação de situações para ativar a participação dos estudantes nos métodos de ensino centrados neles (IMBERNÓN, 2012, p. 51).

Saturnino de la Torre (2008), em seu livro "Estrategias didácticas em el aula. Buscando la calidad y la innovación”, assim se expressa sobre o significado da mediação pedagógica:

O papel do docente em lugar de centrar-se na explicação, assume um caráter estimulador mediador, criador de cenários e ambientes. Esta é a novidade teórica de nosso planejamento didático. A teoria de didática que defendemos é uma teoria de mediação. As estratégias fazem essa função mediadora integrando teoria e prática (TORRE, 2008, p. 9-10).

Ken Bain (2007) nos apresenta um desafio bem concreto, para essa mudança de atitude dos professores: já pensaram o que aconteceria se o professor em vez de começar o 
semestre letivo "planejando sua disciplina" tomasse a decisão de começá-lo "pensando nos alunos" (BAIN, 2007, p.125), acolhendo-os, procurando conhecer seus interesses pelos quais ali se encontram, quais suas preocupações para sua vida? O que procuram ao virem se formar nesta ou noutra profissão? Quais as novas perspectivas e aberturas da profissão que hoje procuram?

Há muitos anos (MASETTO, 2010, 2012, 2015) em nossas vivências pedagógicas no Ensino Superior, vimos desenvolvendo uma Metodologia de Acolhimento do Aluno no Primeiro Encontro, ao se iniciar uma disciplina, que tem por objetivo conhecimento dos alunos e suas expectativas com relação à sua profissão, iniciar uma comunidade de aprendizagem que, com o professor, construa seus objetivos de formação, discuta os grandes temas daquela área de conhecimento, dialogue sobre técnicas e métodos que lhes permitam participar e construir sua apendizagem e planejar um prcesso de avaliação. Construimos em parceria o plano de trabalho da disciplina.

Este primeiro encontro nosso com os alunos tem respondido às perguntas de Bain (2007) com uma atitude de protagonismo dos alunos em seu curso universitário e provocado o desenvolvimento de uma mediação pedagógica por nossa parte criando um clima de confiança , respeito, diálogo, colaboração e valorização da comunidade de aprendizagem.

O desafio de Bain (2007) é explicitado por Zabalza (2004) quando escreve:

\begin{abstract}
Antes do compromisso com sua disciplina, está o compromisso do docente com seus alunos, motivo pelo qual ele deve servir como facilitador, fazendo o que estiver ao seu alcance para que os alunos tenham acesso intelectual aos conteúdos e às práticas da disciplina. Por isso, fala-se atualmente na dupla competência dos bons professores: competência científica (no âmbito de sua áreaespecífica de conhecimento), e competência pedagógica, como pessoas comprometidas com a aformação e com a aprendizagem de seus estudantes [...]. Refletir sobre nossa disciplina, não a partir dela mesma, (como se o objetivo fosse traduzir um manual do programa) mas a partir das expectativas dos estudantes (ZABALZA, 2004, p. 169-170).
\end{abstract}

O professor que sai de trás de sua mesa e vem trabalhar em conjunto com seus alunos, compondo grupos, discutindo as questões que surgem, ajudando a buscar soluções e corrigindo rotas, apoiando seus alunos e aprendendo com eles. Desse modo cria "um ambiente colaborativo de aprendizagem" no qual as figuras do aluno e do professor se integram em ações partilhadas, promovendo transformações e a construção conjunta do conhecimento e da formação profissional.O Professor que interage com os alunos com uma atitude de parceria e corresponsabilidade pelo processo de aprendizagem. 
O professor como Mediador Pedagógico que estabelece com seus alunos uma relação entre adultos, uma relação andragógica no sentido de que ambos tem condições cognitivas e emocionais "de se interessarem em alcançar alguns objetivos comuns e perceberem que poderão consegui-lo mais facilmente se trabalharem em conjunto, com respeito mútuo, com diálogo, integrando forças de modo corresponsável e parceiro" (MASETTO, 2010, p.44-45).

Zabalza (2004) comenta:

Os alunos ingressam na universidade com alguns interesses profissionais definidos. Ou seja, por serem clientes, fazem certas exigências específicas à instituição. Isso leva a universidade a ampliar e diversificar a oferta da formação, de maneira que se adapte melhor às expectativas diferenciadas dos alunos [...]. Uma das prerrogativas dos adultos é que eles 'sabem o que querem'[...] têm o direito de traçar um projeto de vida. Levar em conta a condição de 'adultos' dos estudantes serviu como ponto de partida importante para inovações significativas na universidade (ZABALZA, 2004, p. 187-188).

Uma relação andragógica incentivará o estabelecimento de um contrato pedagógico entre alunos e professor no início de uma disciplina, que permita a construção em parceria do programa de trabalho a ser realizado, atendendo: a objetivos de formação profissional estabelecidos de comum acordo entre alunos e professor; a definição de conteúdos levando em consideração sua relevância, atualidade, utilidade e significado para os alunos e a possibilidade de aplicações; a utilização de estratégias (metodologias ativas) que motivem pessoas adultas para que participem ativamente; a criação com os alunos de um clima de aula que seja de abertura, de questionamentos, de respeito mútuo, de troca de experiências, de exposição de ideias fundamentadas; e por fim, a elaboração com os alunos de um processo de avaliação que seja um acompanhamento do aluno em suas atividades oferecendo-lhe um feedback contínuo, dialogado, gerando orientações para o seu desenvolvimento.

Para que um processo de aprendizagem possa efetivamente levar um sujeito a alcançar seus objetivos ele precisa de um outro sistema, um outro processo que se integre a ele e o acompanhe em todos os momentos de formação do aprendiz, oferecendo informações (feedbacks) de acordo com as necessidades: correção quando houver um erro, orientação quando há dificuldade de avançar, incentivo nos momentos de desânimo do aluno, apresentação de atividades diferenciadas para impulsionar a aprendizagem. Ou seja, no 
movimento de altos e baixos de um processo de aprendizagem há necessidade de que possamos contar com a atitude do professor que acompanhe seus alunos nesse processo.

Sintetizando, um Professor Mediador Pedagógico, como:

profissional das relações pedagógicas, que interage de forma adulta com os alunos com uma atitude de respeito, de diálogo, de convite à participação em seu processo de formação, de parceria e corresponsabilidade pelo processo de aprendizagem.

Um Professor Parceiro de seus alunos na construção da aprendizagem e da formação profissional, que muda sua atitude de um especialista que ensina para um profissional da aprendizagem, que planeja situações de aprendizagem de seus alunos, que incentiva e motiva o aprendiz, que se apresenta com a disposição de ser uma ponte viva, dinâmica, flexível entre o aprendiz e sua aprendizagem, entre o aprendiz e sua formação profissional (MASETTO, 2015, p. 93-94).

Professor e aluno parceiros que no cenário de uma sociedade contemporânea, constroem uma aula universitária como um espaço e tempo nos quais agem e interagem através de Metodologias Ativas e de um processo de acompanhamento e nesse intercurso de ações constroem um processo de aprendizagem e de formação profissional cidadã.

\section{CAMINHADO PARA NOSSAS REFLEXÕES FINAIS...}

Propondo-nos como objetivo deste artigo identificar em que condições a utilização das Metodologias Ativas no Ensino Superior faz realmente a diferença na formação de profissionais, apontamos três aspectos imprescindíveis para que esta diferença se manifeste.

$\mathrm{O}$ primeiro tem a ver com uma mudança radical no planejamento dos cursos de graduação: substituir um programa de conteúdos e cronograma por um projeto pedagógico que explicite, a partir das Diretrizes Curriculares Nacionais qual a formação profissional a ser aprendida, envolvendo as áreas do conhecimento, de habilidades e competências, e a de atitudes e valores.

A explicitação destes objetivos de formação permitirá ao docente e ao aluno planejar e implementar o processo de aprendizagem na organização dos conhecimentos (conteúdos), das habilidades e atitudes a serem desenvolvidas, bem como das atividades e práticas profissionais, selecionando as metodologias ativas adequadas e um processo de avaliação condizentes com os objetivos propostos. 
A diversidade dos objetivos de formação profissional e um novo planejamento da disciplina a ser ministrada exigirá dos professores mudanças profundas na concepção de seu papel para a docência universitária: substituir a característica de expert em determinado ramo da ciência e de transmissor dessas informações aos alunos por um papel de Mediador Pedagógico, parceiro do aluno na construção de seus conhecimentos e práticas profissionais, planejador de situações de aprendizagem em suas aulas, que poderão acontecer em diferentes ambientes: (presencial, virtual e profissional). Neste planejamento de situações de aprendizagem, o professor estará apto a selecionar entre as Metodologias Ativas aquelas que mais se prestam a colaborar com os alunos para alcançarem os objetivos propostos,

A mudança de atitude do professor para compreender que o aluno é sujeito de sua formação e que pode e deve dividir com êle, professor, a responsabilidade pela sua construção; que a participação concreta nas atividades de aprendizagem é esperada; que há uma necessidade de dialogar com o aluno, ouví-lo, respeitá-lo, orientá-lo e principalmente compreender que o aluno chega à universidade para aprender com êle, professor, e com os colegas e não para ser ensinado, tem exigido programas específicos de formação dos professores que possam ajudá-los e apoiá-los nesta inovação da profissão de docentes.

Quando os alunos percebem que as aulas lhes permitem estudar, discutir e encontrar pistas e/ou encaminhamentos para problemas que existem em sua vida real e na via dos demais homens que constituem seu grupo social, e sentem que podem deixar a aula com 'mãos cheias' de dados novos e contribuições significativas para os problemas que são vividos 'para além das paredes das aulas', este espaço começa a ser um espaço de vida e, por isso mesmo, assume um interesse peculiar para o grupo (MASETTO, 2010, p. 38).

As Metodologias Ativas são estratégias muito importantes para incentivar o protagonismo do aluno na construção de seu processo de formação profissional. Mas, realmente, só farão a diferença na formação de nossos profissionais se foram utilizadas tendo em vista a formação de profissionais com competência e cidadania exigidas pela contemporaneidade e trabalhadas, em parceria por professores mediadores de um processo de aprendizagem e alunos protagonistas do mesmo. 


\section{REFERÊNCIAS}

BACICH, Lilian; MORAN, José. Metodologias Ativas para uma educação inovadora, Porto Alegre: Penso, 2018.

BAIN, Ken. Lo que hacen los mejores profesores universitários. Valencia: Universitat de Valencia, 2007.

HARGREAVES, Andy. O Ensino na sociedade do conhecimento: educação na era da insegurança. Porto Alegre: ArtMed, 2004.

IMBERNÓN, Francisco. Inovar o Ensino e a Aprendizagem na Universidade. São Paulo: Cortez, 2012.

MASETTO, Marcos T. (Org.). Ensino de Engenharia: técnicas para otimização das aulas. São Paulo: Avercamp, 2007.

MASETTO, Marcos T. O Professor na Hora da Verdade. São Paulo: Avercamp, 2010.

MASETTO, Marcos T. Competência pedagógica do professor universitário. 2. ed.rev. São Paulo: Summus, 2012.

MASETTO, Marcos T. Desafios para a Docência Universitária na Contemporaneidade: professor e aluno em inter-ação adulta. São Paulo: Avercamp, 2015.

POZO, Juan Ignacio. Aprendizes e Mestres. Porto Alegre: Artmed, 2002.

TORRE, Saturnino de la. (Org.). Estrategias didácticas em el aula: buscando la calidad y la innovación. Madri: Universidad Nacional de Educación a Distancia, 2008.

UNESCO. Declaração Mundial sobre Educação Superior no Século XXI: Visão e Ação. Paris, 1998. Missões e Funções da Educação Superior. Piracicaba: Unimep,1998.

VEEN W.; VRAKKING, B. Homo zappiens: educando na era digital. Porto Alegre: Artmed, 2009.

ZABALZA, Miguel A. O estágio e as práticas em contextos profissionais na formação universitária. São Paulo: Cortez, 2014.

ZABALZA, Miguel A. O Ensino Universitário, seu cenário e seus protagonistas. Porto Alegre: Artmed, 2004. 